\title{
Leucemia de células velludas en el embarazo. Caso clínico
}

\author{
ANDREA BUSTAMANTE ${ }^{2}$, MARÍA ALEJANDRA RODRÍGUEZ1, \\ MAURICIO OCQUETEAU ${ }^{1}$, PABLO BERTIIN ${ }^{1}$, PABLO LIRA ${ }^{1}$, JOSÉ VALBUENA $^{3}$
}

'Departamento de Hematología y Oncología, Pontificia Universidad Católica de Chile.

${ }^{2}$ Servicio de Medicina, Hospita de Urgencia Asistencia Pública. 3epartamento de Anatomía Patológica, Pontificia Universidad Católica de Chile.

Recibido el 10 de marzo de 2010, aceptado el 27 de septiembre de 2010 .

Correspondencia a: María Alejandra Rodríguez Lira $85,4^{\circ}$ piso. Santiago. Fax: 6332544 E-mail: marodri@med.puc.cl

\section{Hairy cell leukemia during pregnancy. Report of one case}

Hairy cell leukemia (HCL) is a rare chronic B cell lymphoproliferative disorder that affects mostly men. It usually presents with pancytopenia, splenomegaly and bone marrow infiltration, without lymphadenopathy. Diagnosis is based on the presence of mononuclear cells with cytoplasmic projections in a blood smear, the typical bone marrow infiltration pattern and the immunophenotypic profile. HCL occurs seldom in young women and even more exceptionally during pregnancy. We report a 31-year-old woman in whom a splenomegaly was detected during routine prenatal care. Pancytopenia with 25\% of hairy cells was found in her blood count. The patient was subjected to an open splenectomy and had an uneventful pregnancy. After two years of follow up, she has a normal blood count and has not required chemotherapy.

(Rev Med Chile 2010; 138: 1422-1428).

Key words: Leukemia, hairy cell; Pregnancy complications; Splenectomy.
L a leucemia de células velludas (LCV) fue descrita por primera vez en 1920 y nominada de muchas formas (reticuloendoteliosis leucémica, leucemia histiocítica, reticulosis maligna y mielofibrosis linfoidea). En 1958 se caracterizó por Bouroncle como una entidad única con características clínicas e histopatológicas distintivas ${ }^{1}$. El término célula velluda fue acuñado en 1966 por Schrek y Donnelly basándose en observaciones microscópicas de las proyecciones citoplasmáticas de los linfocitos patológicos ${ }^{2}$.

Se trata de un desorden linfoproliferativo crónico de células B muy infrecuente. Esta enfermedad representa $2-3 \%$ de todas las leucemias, con una incidencia estimada en población norteamericana de 0,3 casos por 100.000 habitantes $^{3}$. Existe una predominancia masculina 4-5:1 y la edad promedio al diagnóstico es de 52 años $^{4}$.

La leucemia de células velludas es una enfermedad infrecuente, de evolución larvada, con múltiples presentaciones. Además puede coexistir con otras neoplasias, dificultando y atrasando el diagnóstico.

La LCV no es frecuente en la subpoblación de mujeres jóvenes y menos aún embarazadas, existiendo escasos reportes en la literatura ${ }^{5-7}$.

\section{Caso}

Paciente de 31 años, sexo femenino, con antecedente de depresión mayor en tratamiento ambulatorio irregular. En control por embarazo de 17 semanas, notó una masa y molestia en hipocondrio izquierdo, por lo que consultó a su obstetra. Preguntado en forma dirigida, tenía saciedad precoz en los últimos 2 años.

Se realizó una ecografía abdominal que objetivó esplenomegalia de $27 \mathrm{~cm}$, por lo que se hospitalizó para estudio.

En hemograma de ingreso se pesquisó pancitopenia (hematocrito $20,1 \%$, hemoglobina $6,9 \mathrm{~g} / \mathrm{dL}$, 
Leucemia de células velludas en el embarazo - A. Bustamante et al

leucocitos $2.600 / \mathrm{mm}^{3}$, RAN 900/(mm ${ }^{3}$, RAL $1.700 /$ $\mathrm{mm}^{3}$ y plaquetas $91.000 / \mathrm{mm}^{3}$ ) con $25 \%$ de los linfocitos con aspecto velludo (Figura 1). El perfil bioquímico al ingreso fue normal (LDH 167 U/L).

Se realizó citometría de flujo en sangre periférica y biopsia de médula ósea y se transfundieron glóbulos rojos.

En la citometría de flujo se observó 25\% de células linfoides de estirpe $\mathrm{B}$ con patrón de dispersión de luz (FSC/SSC) más alto que lo habitual demostrándose un síndrome linfoproliferativo de estirpe B, kappa, sugerente de leucemia de células velludas [co-expresión de los antígenos CD45

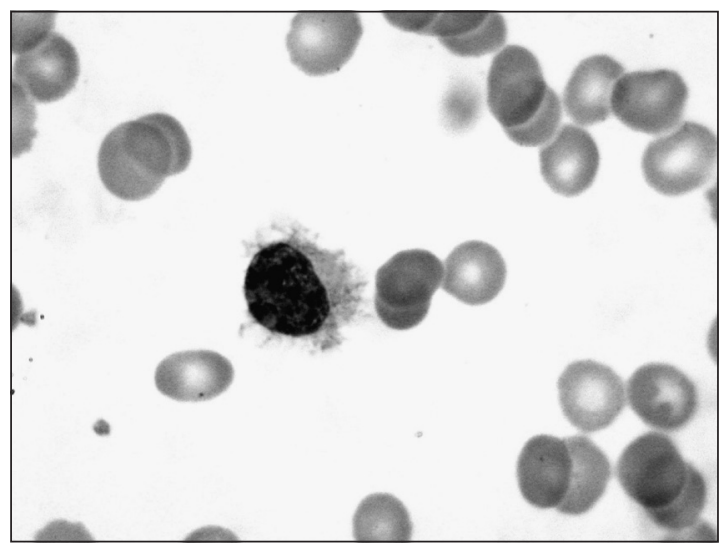

Figura 1. Frotis sanguíneo, se observa al centro célula mononuclear con proyecciones citoplasmáticas típicas (célula velluda).

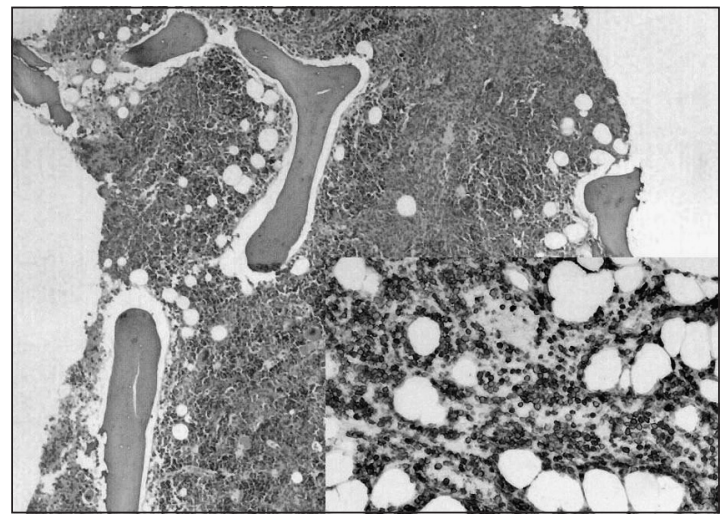

Figura 2. Corte histológico de médula ósea (HE) muestra extensa infiltración por LCV que es resaltado por tinción inmunohistoquímica para CD20 (recuadro). (intenso), CD19 (intenso), CD20 (muy intenso), CD22 (intenso), CD103 (intenso), CD25 (moderado a intenso) y CD11c (muy intenso) en ausencia de marcadores linfoides $\mathrm{T}]$.

En la biopsia de médula ósea destacaba un infiltrado celular de disposición intersticial, en partes formando agregados, constituido por células pequeñas a medianas, de núcleos pequeños, redondos a ovales, levemente pleomórficos y moderada cantidad de citoplasma eosinófilo, con bordes celulares bien definidos (Figura 2). La tinción histoquímica de reticulina demostró fibrosis de retículo $(3+)$, más acentuada en relación a los agregados de células tumorales. Estudios inmunohistoquímicos realizados en cortes histológicos demuestran que las células neoplásicas son inmunorreactivas para CD20 y CD25 y negativas para CD5 y DBA44.

Las series mieloide, eritroide y megacariocítica tenían aspecto normal y estaban discretamente disminuidas.

En conjunto con el equipo obstétrico se decidió realizar una esplenectomía abierta. En el estudio anatomopatológico se observó un bazo de 3.400 gramos, que en la evaluación histológica demostró un extenso compromiso difuso de la pulpa roja por LCV y formación de lagunas "rojas" características en esta patología (Figura 3).

No presentó complicaciones quirúrgicas y completó una gestación de término con un hijo sano.

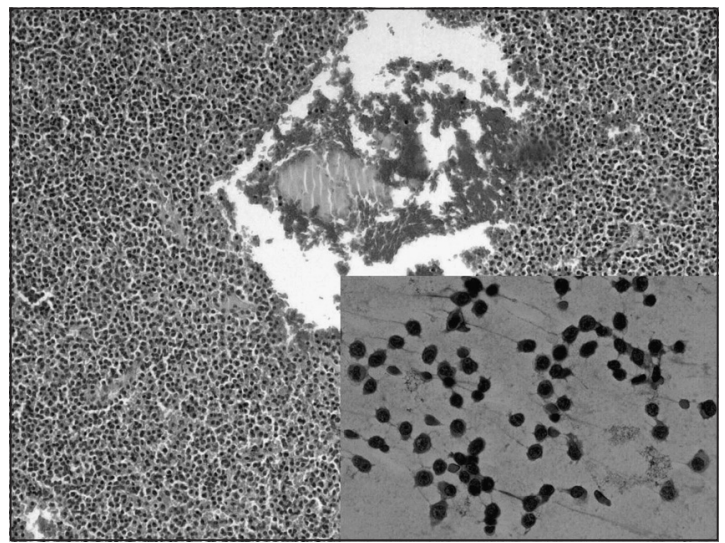

Figura 3. Corte histológico de bazo (HE) muestra extenso compromiso de pulpa roja con formación de lagunas "rojas". Impronta de bazo muestra células neoplásicas de mediano tamaño de aspecto monocitoide (recuadro). 
La paciente se ha mantenido en control periódico con el equipo de hematología. Su hemograma se normalizó y no presenta indicación de inicio de quimioterapia a los dos años y medio de observación.

\section{Discusión}

\section{Diagnóstico}

Los pacientes con LCV tienen frecuentemente pancitopenia, esplenomegalia e infiltración de médula ósea, sin linfadenopatías. El diagnóstico se basa en la presencia de células mononucleares con proyecciones citoplasmáticas en el frotis sanguíneo, el patrón histológico típico de infiltración en la médula ósea y el perfil inmunofenotípico.

Esta enfermedad tiene generalmente un curso indolente y es una de las leucemias que se trata con mayor éxito cuando es correctamente diagnosticada. En mujeres embarazadas, como en la mayoría de los pacientes, LCV se pesquisa a raíz de un control de rutina con hemograma o por hallazgo de esplenomegalia.

Actualmente, la clínica combinada con las tinciones inmunohistoquímicas y el patrón inmunofenotípico en la citometría de flujo, permiten el diagnóstico.

Del punto de vista inmunofenotípico (obtenido de sangre periférica o MO) no existe un marcador que sea patognomónico para LCV. La célula velluda es una célula madura, pero no terminalmente diferenciada. Los antígenos asociados a la línea $\mathrm{B}$ tienen una expresión intensa en esta enfermedad, como CD19, CD20, CD22, CD79A, CD40 y FMC7. Generalmente no se expresan CD5, CD21, CD23 ni CD79B. Además hay marcadores más "específicos" de LCV como CD11c, HC-2, CD25 y CD103.

La asociación de estos marcadores constituye el patrón inmunofenotípico característico de $\mathrm{LCV}^{8}$.

La infiltración de médula ósea por células velludas se observa en todos los pacientes. Dado que la aspiración medular habitualmente resulta seca, se recomienda realizar biopsia de médula ósea. La biopsia es generalmente hipercelular, con compromiso difuso y con aumento de las fibras de reticulina, causando eventualmente fibrosis medular. Con menor frecuencia se observa compromiso focal e incluso hipocelularidad. En estos casos la inmunohistoquímica aporta más información. Los anticuerpos monoclonales usados para estas tinciones incluyen anti-CD20 y DBA44, usualmente positivos en forma intensa en $\mathrm{LCV}^{9}$.

\section{Tratamiento}

El tratamiento de LCV se considera en pacientes sintomáticos o citopénicos. Se recomienda el inicio de la terapia si el paciente tiene neutropenia significativa $\left(<1.000 / \mathrm{mm}^{3}\right)$, trombocitopenia $\left(<100.000 / \mathrm{mm}^{3}\right)$, anemia $(<11 \mathrm{~g} / \mathrm{dL})$, esplenomegalia sintomática, síntomas generales debido a LCV, infecciones serias recurrentes, linfadenopatías dolorosas o voluminosas, leucocitosis ( $>20.000 / \mathrm{mm}^{3}$ ) con alta proporción de células velludas, vasculitis y compromiso óseo ${ }^{10}$.

Se han utilizado una variedad de herramientas para el tratamiento de LCV. Primero sólo se realizaba esplenectomía, luego se usó interferón alfa hasta que se introdujeron los análogos de purinas con mejores resultados. La terapia más reciente en estudio son los anticuerpos monoclonales.

Actualmente, la terapia de elección en LCV son los análogos de purinas cladribina y pentostatina debido a su fácil administración, corta duración de la terapia, alta tasa de respuesta, con un perfil de toxicidad aceptable ${ }^{11}$.

Sin embargo, no se pueden usar análogos de las purinas durante el embarazo debido al potencial teratogénico demostrado en animales (aborto, micro-oftalmia, acortamiento del tronco, hernia lumbar, espina bífida, anormalidades de tejidos blandos, renales y cardíacos $)^{12}$.

Para las pacientes embarazadas con indicación de inicio de tratamiento, no existe terapia estándar. Hay escasos reportes de tratamientos que se han indicado en mujeres embarazadas.

La esplenectomía puede indicarse en pacientes que desarrollan LCV durante el embarazo como tratamiento provisorio, incluso permitiendo dar un tiempo de lactancia, antes de iniciar la quimioterapia ${ }^{5,13}$. Usada como primera herramienta en LCV, logra mejorar e incluso normalizar las citopenias por 5-20 meses en hasta $80 \%$ de los pacientes ${ }^{14,15}$. Este procedimiento lograba una remisión total de la enfermedad hasta en $40 \%{ }^{16}$ y en un análisis retrospectivo prolongaba la sobrevida ${ }^{17}$.

También hay reportes del uso de interferón alfa en el embarazo, dado que el interferón alfa no inhibe la síntesis de $\mathrm{ADN}^{6}$. Este se introdujo a principios de los ' 80 s mejorando el pronóstico de LCV, superando a la esplenectomía ${ }^{18}$. La mayoría 
de los pacientes alcanzan respuestas parciales, los que responden tienen una sobrevida a 5 años de hasta $90 \%$, pero en general los pacientes sin terapia de mantención recaen luego de terminar el tratamiento ${ }^{19}$. Por esto es necesario completar la terapia luego del parto. Las desventajas del interferón alfa son su alto costo, requerimiento de largas mantenciones y efectos secundarios frecuentes como síntomas tipo gripe, pérdida de la memoria, depresión, mialgias, anorexia y fatiga ${ }^{20}$.

Finalmente, hay nuevos agentes que se han probado para LCV en la práctica clínica, entre los cuales destacan el anticuerpo monoclonal rituximab y el inmunoconjugado BL22 ${ }^{11}$.

Existen reportes de tratamiento con rituximab durante el embarazo en el primer y segundo trimestre con buen resultado obstétrico ${ }^{21-22}$.

Se ha evaluado la toxicidad fetal de rituximab en pacientes embarazadas, y se ha reportado depleción transitoria de células B asociada a altas concentraciones de rituximab en sangre del cordón umbilical. La recuperación es rápida, con un inmunofenotipo normal sin pérdida del antígeno CD20. No se han observado otras consecuencias ${ }^{23}$.

Las terapias moleculares podrían ser consideradas en la paciente embarazada portadora de LCV con indicación de inicio de tratamiento, cuando su sobrevida esté amenazada al tener que esperar varios meses para el inicio de la terapia tradicional ${ }^{24}$.

Aún se están investigando esquemas terapéuticos con estos compuestos y se requieren seguimientos más largos a un mayor número de pacientes para determinar su utilidad en LCV.

\section{Discusión del caso clínico}

Esta paciente debutó con esplenomegalia y pancitopenia durante su segundo trimestre de embarazo. En el frotis sanguíneo se observaron células velludas, orientando rápidamente hacia el diagnóstico de LCV con indicación de tratamiento.

$\mathrm{Al}$ evaluar las opciones terapéuticas, se descartó la quimioterapia debido a los riegos descritos para el feto.

Se decidió realizar una esplenectomía abierta para aliviar los síntomas y las citopenias. Si bien la ruptura esplénica espontánea es una complicación infrecuente de alta mortalidad, en el embarazo aumenta su riesgo, secundario a la compresión diafragmática durante las contracciones uterinas ${ }^{25}$.
El momento elegido para la esplenectomía fue el segundo trimestre, ya que técnicamente es más fácil de realizar que en el tercer trimestre debido al tamaño uterino y es el estimado de menor riesgo para la mantención del embarazo ${ }^{26}$.

La paciente evolucionó en forma favorable, normalizando las citopenias luego de la esplenectomía. Tuvo un parto de término a las 40 semanas de gestación, con un recién nacido saludable y una lactancia prolongada por más de seis meses.

Actualmente, el hijo tiene más de dos años, presenta un buen desarrollo psicomotor y no tiene problemas ponderales.

La paciente permanece en control, no presenta linfocitos velludos circulantes, tampoco citopenias, por lo que no ha requerido inicio de quimioterapia aún.

\section{Referencias}

1. Bouroncle BA, Wisemann BK, Doan CA. Leukemic reticuloendotheliosis. Blood 1958; 13: 609-30.

2. Schrek R, Donnelly WJ. "Hairy" cells in blood in lymphoreticular neoplastic disease and "flagellated" cells of normal lymph nodes. Blood 1966; 27: 199-211.

3. Morton LM, Wang SS, Devesa SS, et al. Lymphoma incidence patterns by WHO subtype in the United States. 1992-2001. Blood 2006; 107: 265-76.

4. Bernstein L, Newton P, Ross RK. Epidemiology of hairy cell leukemia in Los Angeles County. Cancer Res 1990; 50: 3605-9.

5. Alothman A, Sparling TG. Managing hairy cell leukemia in pregnancy. Ann Intern Med 1994; 120: 1048-9.

6. Baer MR, Ozer H, Foon KA. Interferon-a therapy during pregnancy in chronic myelogenous leukaemia and hairy cell leukaemia. Br J Haematol 1992;81:167-9.

7. Williams JK. Hairy cell leukemia in pregnancy: a case report. Am J Obstet Gynecol 1987; 156: 210-1.

8. Polliack A. Hairy cell leukemia: biology, clinical diagnosis, unusual manifestations and associated disorders. Rev Clin Exp Hematol 2002; 6: 366-88.

9. Foucar K, Catovsky D. Pathology \& Genetics: Tumours of Hematopoietic and Lymphoid Tissues. Lyon: IARC Press; 2001: 138-41

10. Goodman GR, Bethel KJ, Saven A. Hairy cell leukemia: an update. Curr Opin Hematol 2003; 10: 258-66

11. Gidron A, Tallman MS. 2-CdA in the treatment of hairy cell leukemia: a review of long-term follow-up. Leuk Lymphoma 2006; 47: 2301-7.

12. Lau C, Narotsky MG, Lui D, et al. Exposure-disease 
continuum for 2-chloro-2'-deoxyadenosine (2-CdA), a prototype teratogen: induction of lumbar hernia in the rat and species comparison for the teratogenic responses. Teratology 2002; 66: 6-18.

13. Stiles GM, Stanco LM, Saven A, Hoffmann KD. Splenectomy for hairy cell leukemia in pregnancy. J Perinatol 1998; 18: 200-1.

14. Saven A, Piro LD. Treatment of hairy cell leukemia. Blood 1992; 9: 1111-20.

15. Van Norman AS, Nagorney DM, Martin JK, et al. Splenectomy for hairy cell leukemia: a clinical review of 63 patients. Cancer 1986; 57: 644-8.

16. Zakarija A, Peterson LC, Tallman MS. Splenectomy and treatment of historical interest. Best Pract Res Clin Haematol 2003; 16: 57-68.

17. Jansen J, Hermans J. Splenectomy in hairy cell leukemia: a retrospective multicenter analysis. Cancer 1981; 47: 2066-76.

18. Smalley RV, Connors J, Tuttle RL, et al. Splenectomy vs alpha interferon: a randomized study in patients with previously untreated hairy cell leukemia. Am J Hematol 1992; 41: 13-8.

19. Grever M, Kopecky K, Foucar MK, et al. Randomized comparison of pentostatin versus interferon alfa-2a in previously untreated patients with hairy cell leukemia: an Intergroup study. J Clin Oncol 1995; 13: 974-82.

20. Ahmed S, Rai KR. Interferon in the treatment of hairy cell leukemia. Best Pract Res Clin Haematol 2003; 16: 69-81.

21. Kimby E, Sverrisdottir A, Elinder G. Safety of rituximab therapy during the first trimester of pregnancy: a case history. Eur J Haematol 2004; 72: 292-5.

22. Ojeda-Uribe M, Gilliot C, Jung G, et al. Administration of rituximab during the first trimester of pregnancy without consequences for the newborn. J Perinat 2006; 26: $252-5$.

23. Friedrichs B, Tiemann M, Salwender H et al. The effects of rituximab treatment during pregnancy on a neonate. Haematologica 2006; 91: 1426-7.

24. Robinson A, Watson W, Leslie K. Targeted treatment using monoclonal antibodies and tyrosine-kinase inhibitors in pregnancy. Lancet Oncol 2007; 8: 738-43.

25. Reches A, Almog R, Pauzner D, et al. Spontaneous splenic rupture in pregnancy after heparin treatment. BJOG. 2005; 112: 837-8.

26. Moran B, Yano H, Farquharson M. Conflicting priorities in surgical intervention for cancer in pregnancy. Lancet Oncol 2007; 8: 536-44. 